\title{
Pancreatic anastomosis after pancreatoduodenectomy: A position statement by the International Study Group of Pancreatic Surgery (ISGPS)
}

\author{
Shailesh V. Shrikhande, MD, ${ }^{\mathrm{a}}$ Masillamany Sivasanker, MD, ${ }^{\mathrm{a}}$ Charles M. Vollmer, MD, ${ }^{\mathrm{b}}$ \\ Helmut Friess, MD, ${ }^{\mathrm{c}}$ Marc G. Besselink, MD, ${ }^{\mathrm{d}}$ Abe Fingerhut, MD, ${ }^{\mathrm{e}}$ Charles J. Yeo, MD, ${ }^{\mathrm{f}}$ \\ Carlos Fernandez-delCastillo, MD, ${ }^{\mathrm{g}}$ Christos Dervenis, MD, ${ }^{\mathrm{h}}$ Christoper Halloran, MD, ${ }^{\mathrm{i}}$ \\ Dirk J. Gouma, MD, ${ }^{d}$ Dejan Radenkovic, MD, ${ }^{j}$ Horacio J. Asbun, MD, ${ }^{k}$ John P. Neoptolemos, MD, \\ Jakob R. Izbicki, MD, ${ }^{1}$ Keith D. Lillemoe, MD, ${ }^{\mathrm{g}}$ Kevin C. Conlon, MD, ${ }^{\mathrm{m}}$ \\ Laureano Fernandez-Cruz, MD, ${ }^{\mathrm{n}}$ Marco Montorsi, MD, ${ }^{\circ}$ Max Bockhorn, $\mathrm{MD},{ }^{1}$ Mustapha Adham, MD, ${ }^{\mathrm{p}}$ \\ Richard Charnley, MD, ${ }^{\mathrm{q}}$ Ross Carter, MD, ${ }^{\mathrm{r}}$ Thilo Hackert, MD, ${ }^{\mathrm{s}}$ Werner Hartwig, MD, ${ }^{\mathrm{t}}$ Yi Miao, MD, ${ }^{\mathrm{u}}$ \\ Michael Sarr, MD, ${ }^{\mathbf{v}}$ Claudio Bassi, MD, ${ }^{\mathrm{w}}$ and Markus W. Büchler, MD, ${ }^{\mathrm{s}}$ for the International Study \\ Group of Pancreatic Surgery (ISGPS) Mumbai, India, Philadelphia, PA, Munich, Hamburg, and \\ Heidelberg, Germany, Amsterdam, The Netherlands, Graz, Austria, Boston, MA, Athens, Greece, Liverpool, \\ Newcastle upon Tyne, and Glasgow, United Kingdom, Belgrade, Serbia, Jacksonville, FL, Dublin, Ireland, \\ Barcelona, Spain, Lyon, France, Nanjing, P.R. China, Rochester, MN, and Verona and Milan, Italy
}

Background. Clinically relevant postoperative pancreatic fistula (grades B and C of the ISGPS definition) remains the most troublesome complication after pancreatoduodenectomy. The approach to management of the pancreatic remnant via some form of pancreatico-enteric anastomosis determines the incidence and severity of clinically relevant postoperative pancreatic fistula. Despite numerous trials comparing diverse pancreatico-enteric anastomosis techniques and other adjunctive strategies (pancreatic duct stenting, somatostatin analogues, etc), currently, there is no clear consensus regarding the ideal method of pancreatico-enteric anastomosis.

Methods. An international panel of pancreatic surgeons working in well-known, high-volume centers reviewed the best contemporary literature concerning pancreatico-enteric anastomosis and worked to develop a position statement on pancreatic anastomosis after pancreatoduodenectomy.

Results. There is inherent risk assumed by creating a pancreatico-enteric anastomosis based on factors related to the gland (eg, parenchymal texture, disease pathology). None of the technical variations of pancreaticojejunal or pancreaticogastric anastomosis, such as duct-mucosa, invagination method, and binding technique, have been found to be consistently superior to another. Randomized trials and metaanalyses comparing pancreaticogastrostomy versus pancreaticojejunostomy yield conflicting results and are inherently prone to bias due to marked heterogeneity in the studies. The benefit of stenting the pancreatico-enteric anastomosis to decrease clinically relevant postoperative pancreatic fistula is not supported by high-level evidence. While controversial, somatostatin analogues appear to decrease perioperative complications but not mortality, although consistent data across the more than 20 studies addressing this topic are lacking. The Fistula Risk Score is useful for predicting postoperative pancreatic fistula as well as for comparing outcomes of pancreatico-enteric anastomosis across studies.

Conclusion. Currently, no specific technique can eliminate development of clinically relevant postoperative pancreatic fistula. While consistent practice of any standardized technique may decrease the rate of clinically relevant postoperative pancreatic fistula, experienced surgeons can have lower postoperative pancreatic fistula rates performing a variety of techniques depending on the clinical situation. There is no clear evidence on the benefit of internal or external stenting after pancreaticoenteric anastomosis. The use of somatostatin analogues may be important in decreasing morbidity after

Accepted for publication November 13, 2016.

Reprint requests: Shailesh V. Shrikhande, MD, Department of Gastrointestinal and HPB Surgical Oncology, Tata Memorial Hospital, Ernest Borges Road, Parel, Mumbai 400012, India. E-mail: shailushrikhande@hotmail.com.
0039-6060/\$ - see front matter

(c) 2016 Elsevier Inc. All rights reserved.

http://dx.doi.org/10.1016/j.surg.2016.11.021 
pancreatoduodenectomy, but it remains controversial. Future studies should focus on novel approaches to decrease the rate of clinically relevant postoperative pancreatic fistula with appropriate risk adjustment. (Surgery 2016; $\mathbf{\square}: \mathbf{\square}$.)

From the Department of Gastrointestinal and HPB Surgical Oncology, ${ }^{a}$ Tata Memorial Hospital, Mumbai, India; Department of Surgery, ${ }^{b}$ University of Pennsylvania, Philadelphia, PA; Department of Surgery, ${ }^{c}$ Klinikum Rechts der Isar, Technische Universitat Munchen, Munich, Germany; Department of Surgery, ${ }^{d}$ Academic Medical Center, University of Amsterdam, Amsterdam, The Netherlands; Department of Digestive Surgery, ${ }^{e}$ University Hospital of Graz, Austria; Department of Surgery, ${ }^{f}$ Jefferson Pancreas, Biliary and Related Cancer Center, Thomas Jefferson University, Philadelphia, PA; Department of Surgery, ${ }^{g}$ Massachusetts General Hospital, Harvard Medical School, Boston, MA; Department of First Surgery, ${ }^{h}$ Agia Olga Hospital, Athens, Greece; Department of Molecular and Clinical Cancer Medicine, ${ }^{i}$ University of Liverpool, Liverpool, United Kingdom; First Surgical Clinic, ${ }^{j}$ Clinical Center of Serbia, University of Belgrade, Belgrade, Serbia; Department of General Surgery, ${ }^{k}$ Mayo Clinic, Jacksonville, FL; Department of General, Visceral and Thoracic Surgery, ${ }^{l}$ University Hospital Hamburg-Eppendorf, Hamburg, Germany; Professorial Surgical Unit, ${ }^{m}$ University of Dublin, Trinity College, Dublin, Ireland; Department of Surgery, ${ }^{n}$ Clinic Hospital of Barcelona, University of Barcelona, Barcelona, Spain; Department of Surgery, ${ }^{\circ}$ Humanitas University, Milan, Italy; Department of Digestive $\mathcal{E}$ FPB Surgery, ${ }^{p}$ Hopital Edouard Herriot, HCL, UCBL1, Lyon, France; Department of HPB Eु Transplant Surgery, ${ }^{q}$ Freeman Hospital, Newcastle upon Tyne, United Kingdom; Glasgow Royal Infirmary, ${ }^{r}$ Glasgow, United Kingdom; Department of General, Visceral and Transplantation Surgery, ${ }^{s}$ University of Heidelberg, Heidelberg, Germany; Department of Surgery, ${ }^{t}$ Klinikum Großhadern, University of Munich, Munich, Germany; Pancreas Center, ${ }^{u}$ Nanjing Medical University, Nanjing, P.R. China; Department of Gastroenterologic and General Surgery, "Mayo Clinic, Rochester, MN; and the Department of Surgery and Oncology, ${ }^{w}$ Pancreas Institute, University Hospital Trust of Verona, Verona, Italy

Pancreatoduodenectomy (PD) remains the gold standard for management of patients with pancreatic head and periampullary neoplasms and also in managing some benign diseases. The procedure is now safe when performed in most high-volume institutions and has an operative mortality of less than $3 \%-5 \% .{ }^{1}$ Despite the low mortality, overall morbidity remains high principally due to the development of a clinically relevant, postoperative pancreatic fistula (CR-POPF) in about $11 \%$ of patients. ${ }^{2,3}$

The potential consequences of CR-POPF are intra-abdominal collections, delayed gastric emptying (DGE), reoperation, post-pancreatectomy hemorrhage (PPH), increased hospital stay, readmission, and increased mortality risk. The well known risk factors for CR-POPF include a soft pancreas, a small main pancreatic duct, its posterior location, underlying disease pathology that does not dilate the main pancreatic duct (eg, bile duct cancer), decreased regional blood supply, and surgeon experience. ${ }^{4}$

The approach to management of the pancreatic remnant and creation of some form of pancreaticoenteric anastomosis (PA) remain key factors in determining the chance of developing a CR-POPF. In an effort to develop evidence-based concepts, several trials have been conducted to study the efficacy of anastomotic techniques (invagination versus duct-to-mucosa), site of the enteric connection (pancreaticojejunostomy $[\mathrm{PJ}]$ versus pancreaticogastrostomy $[\mathrm{PG}]$ ), use of pancreatic duct stenting, fibrin glue, etc, as well as manipulation using various somatostatin analogues.

Despite these efforts, the data are neither consistent nor convincing to the unbiased, critical reader, and there is no clear consensus on how to approach a PA that would best suit a specific situation to decrease the rate of CR-POPF and its potential sequelae. The purpose of this study was to critically evaluate the evidences and form a consensus for constructing the optimum PA in various clinical situations.

\section{METHODS}

In order to formulate a position statement on the optimum method of PA that should be performed after PD, an extensive search strategy was adapted to identify relevant studies and meta-analyses in PubMed and Cochrane databases (Fig). Only articles relevant to PA with English-language abstracts and those published from January 1995 until December 2015 were included. Medical subject headings and keywords included pancreatoduodenectomy, pancreaticoduodenectomy, pancreaticojejunostomy, pancreaticogastrostomy, pancreatic fistula, pancreatic stenting, somatostatin, octreotide, and fistula risk. Note that every attempt was made to define the rate of pancreatic fistula by the International Study Group of Pancreatic Fistula (ISGPF) definition of a CR-POPF according to the 2016 update of the original 2005 ISGPF definition. ${ }^{5}$ 


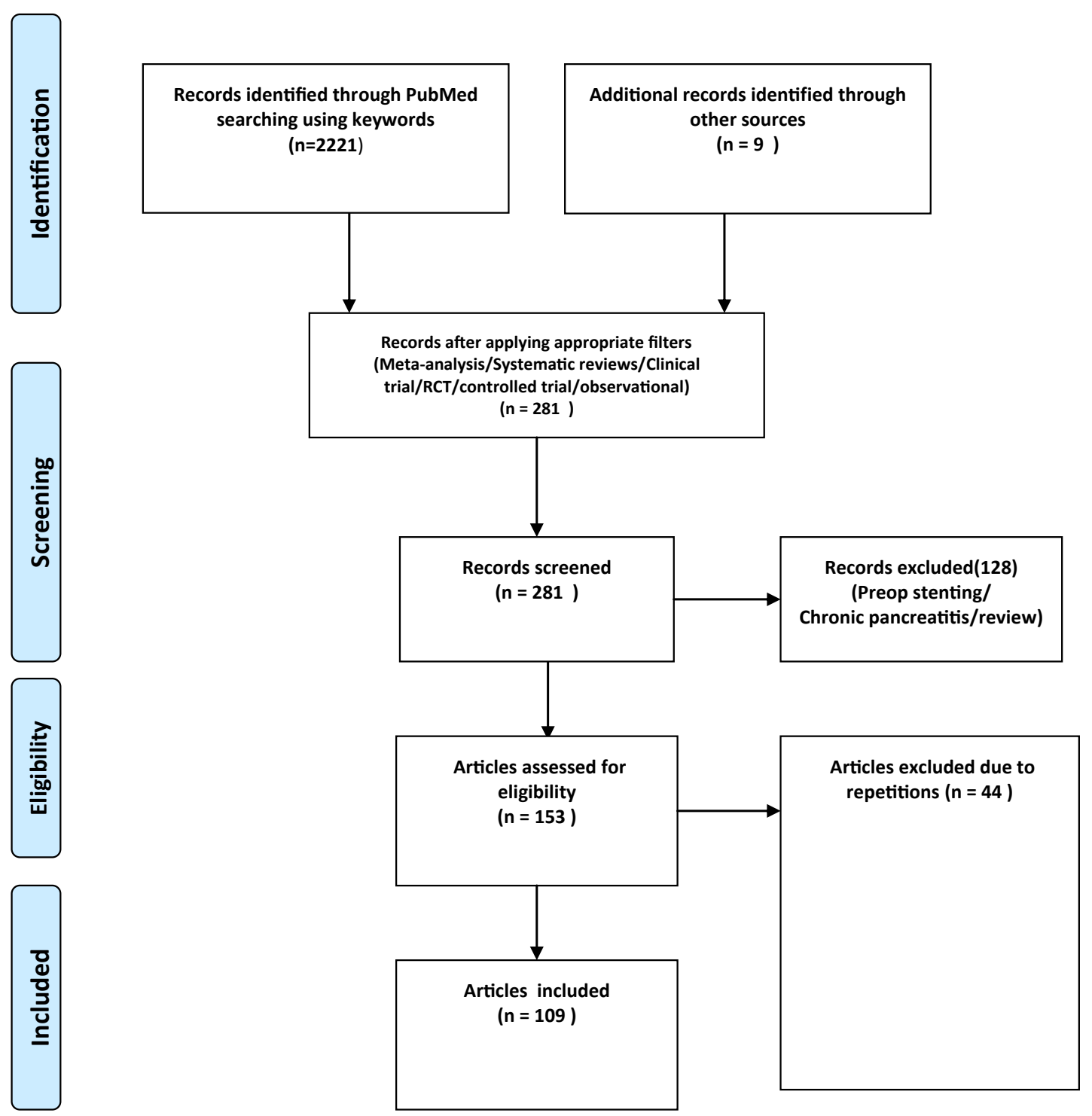

Fig. Search strategy for Identifying relevant studies. Keywords: pancreaticogastrostomy, pancreaticojejunostomy, pancreatoduodenectomy, pancreatic fistula, stenting, somatostatin, Octreotide, isolated loop reconstruction, prophylactic drainage, tissue sealant, fistula risk score with Boolean operators.

Terms were combined with Boolean operators. The levels of evidence were rated in descending order; the studies reviewed included systematic reviews and meta-analyses of randomized controlled trials (RCTs) comparing anastomotic techniques for PA, role of stenting, and somatostatin analogues; prospective RCTs comparing anastomotic techniques, stenting versus no stenting, and role of somatostatin analogues; role of prophylactic drains; and lastly, large observational series on anastomotic techniques categorized according to the evidence level of individual studies as per the recommendations of the Centre for
Evidence-based Medicine, Oxford, United Kingdom (http://www.cebm.net/).

The search was performed up until December 2015; however, articles published in 2016 were also included by the authors if they were deemed to be relevant to the subject. Title and abstract and subsequently full-text articles of all potentially relevant studies were screened by 3 independent reviewers (S.V.S., M.G.S., and M.S.). The concept of the review and summary of the extracted data were sent to all ISGPS participants. Comments and suggestions were reviewed and multiple drafts were circulated thrice to every member of the group 
prior to the European Pancreas Club Meeting in Liverpool in July 2016. Here the group met twice to discuss all issues at length and only then a consensus was reached.

The scope for bias was thus potentially eliminated, since there was active contribution and participation by each of the ISGPS authors during the circulation of the manuscript, and their opinions were in an open forum in electronic communication for others to concur or contradict. The scope for the cognitive bias of framing effects has been limited, since the data were presented as it is without any positive or negative framing for the ISGPS authors to review and opine.

The consensus on the strategy for managing various clinical scenarios during the construction of a PA was derived by the opinion of all ISGPS members by responding to a questionnaire comprising multiple-choice answers, and the rating was based on the strength of concurrence upon responses from members. The position statement was finally formulated by the ISGPS during the European Pancreatic Club meeting using the guidelines of the Grading of Recommendations Assessment, Development, and Evaluation. ${ }^{6}$ The final draft was then read and approved by all the authors prior to submission.

\section{RESULTS}

Technique. Pancreaticojejunostomy (PJ). The various techniques of pancreaticojejunal anastomosis include end-to-side invagination, duct-tomucosa, and the "binding technique" using a single- or double-layer technique. ${ }^{7,8}$ Many nonrandomized studies have suggested that a duct-tomucosa anastomosis is associated with a lower POPF rate compared to an invagination anastomosis; most of these studies, however, are observational with fistula rates up to $20 \%,{ }^{9}$ and the definition of a POPF was not consistent.

A duct-to-mucosa anastomosis can be difficult technically when dealing with a soft, friable, and fatty pancreas with a small duct. Hence, techniques of an invaginating PA have been recommended when dealing with a soft pancreas. ${ }^{10}$ In an RCT involving 197 patients by Berger et al, ${ }^{7}$ the rate of CR-POPF was $17 \%$ in the duct-tomucosa group vs $7 \%$ in the invagination group. The potential criticisms of this study were that the techniques for invagination were not standardized, and unknown surgeon factors, such as intersurgeon variability, varying skillsets, and pancreatic surgery experience, could have confounded the outcomes. Bassi et $\mathrm{al}^{11}$ reported a pancreatic fistula rate of $13 \%$ using the ductto-mucosa technique vs $15 \%$ using a single-layer (capsule to serosa), end-to-side PJ in an RCT involving 144 patients; however, surprisingly, this group did not use the definition of a pancreatic fistula as according to the ISGPF.

In another RCT involving 132 patients randomized to invagination versus duct-to-mucosa, the CRPOPF rate was less in the duct-to-mucosa group (3\% vs $18 \%, P=.004) .{ }^{12}$ In another RCT, a binding PJ showed an almost unbelievable decreased pancreatic fistula rate $(0 \%$ vs $7.2 \%$; note, however, that the ISGPF definition of a POPF and the grading were not used), as well as a decreased duration of hospital stay when compared with a conventional PJ technique. ${ }^{8}$ Further trials, however, could not validate the benefit of this binding technique over other techniques. ${ }^{13,14}$ In a retrospective study involving 182 patients, blumgart anastomosis (transpancreatic U-suture technique) was compared with the duct-mucosa technique, and POPF rates $(13 \%$ vs $4 \%, P=.032$ ) were found to be lower in the blumgart anastomosis. ${ }^{15}$ However, further randomized studies are being undertaken.

Optimizing the blood supply to the remnant pancreas has been shown to be associated with a low POPF rate using a cutback technique with again a very low fistula rate of $1.6 \%$ (the definition of a fistula did not follow the ISGPF definition) ${ }^{16}$; however, this was an observational cohort study of 123 patients, and further corroborative studies with a higher level of evidence are lacking.

Although high-level evidence on the selection of suture material for the anastomosis is currently lacking, one retrospective study found that the rates of POPF were less with polyester, a synthetic, nonabsorbable material compared to polydioxanone (PDS), a synthetic, absorbable material ${ }^{17}$ $(12 \%$ vs $32 \%, P=.01)$ when applied to the outer layers of PJ anastomoses. This effect was thought to be related to slower, progressive resorption of sutures leading to minor, less severe pancreatic leaks, as attested by the fewer grade C POPFs in the polyester group.

On evaluation of the exocrine insufficiency after a pylorus-preserving PD (PPPD) depending on the type of reconstruction, Jang et $\mathrm{al}^{18}$ comparing PJ versus PG, reported that $95 \%$ of patients developed pancreatic exocrine insufficiency even after PJ at 22 months.

To summarize, current evidence does not support any specific technique for a PJ predominantly due to lack of standardization, inadequate 
experimental designs, and various other confounding factors that can affect outcomes substantially. In current practice, both duct-to-mucosa and invagination techniques of PJ are practiced widely by high-volume surgeons across the world with consistently good results in experienced hands. In a retrospective study, a standardized technique of PJ resulted in a rate of POPF (not the ISGPF definition) of $3.2 \%$, and it was suggested that a standardized technique and consistent practice of a single technique could potentially contribute to a lesser rate of complications. ${ }^{19}$

Pancreaticogastrostomy (PG). PG was suggested as a potential alternative to $\mathrm{PJ}$ with various techniques described in the literature. ${ }^{20,21}$ Several theories, never proven in well-designed trials for some of the favorable outcomes after PG, include the lack of activation of pancreatic enzymes in the acidic gastric luminal environment, favorable topographic anatomy due to the immediate anatomic proximity of the 2 organs and, therefore, less tension on the anastomosis, and the highly vascular stomach promoting healing. Fernandez-Cruz et $\mathrm{al}^{22}$ described a PG with a gastric partitioning technique, where a sleeve of gastric segment with preservation of the gastroepiploic arcade was prepared with a stapler, and an end-to-side, duct-tomucosa PG was constructed.

In the recent RECOPANC trial (see details of relevant trials comparing $\mathrm{PJ}$ and $\mathrm{PG}$ in the section below) that compared PG versus PJ, the authors speculated that although the incidence of CR-POPF was not different after a PG, it may be technically easier for novice surgeons to construct a secure, invaginated PG especially with a soft pancreas. ${ }^{23}$ In a retrospective series from Germany involving 944 patients undergoing PD, 8.4\% developed PPH, and successful endoscopic management was more feasible after a PG compared to PJ ( $31 \%$ vs $9 \%, P=.026)$, although the overall outcomes of PPH were not significantly different between the groups. ${ }^{24}$

In a review of observational cohort studies involving PG reconstruction, the POPF rate was $2.8 \%$ (but the definition of a pancreatic leak was vague at best and did not follow the ISGPF definition), and the mortality in this group was $1.6 \% .^{25}$ Similar to PJ, the lack of clear, convincing, level 1 evidence favoring PG is due largely to the absence of standardization of the technique across various studies. In addition, adequate riskadjustment approaches have not yet been employed in these comparisons.

In addition to immediate morbidity, long-term consequences of the anastomotic construction have been considered. Exocrine insufficiency after PG was studied using ${ }^{13}$-C-labeled, mixed triglyceride breath tests in a cohort of 61 patients; $62 \%$ were diagnosed with pancreatic insufficiency. The independent predictive factors for exocrine insufficiency included preoperative impaired endocrine function, hard pancreatic texture, and main pancreatic duct dilatation caused by PG stricture. ${ }^{26,27}$

Randomized trials of PG versus PJ. There are 9 RCTs that have addressed this issue with varying conclusions. Yeo et $\mathrm{al}^{28}$ in 1995, found similar POPF rates in both groups, and the data did not suggest that one technique was superior over the other. Another study by Bassi et $\mathrm{al}^{29}$ was unable to find any statistically significant difference in POPF rates, but the primary end point was a decrease in postoperative abdominal complications with patients in the PG group showing significantly fewer multiple operative complications (PG $25 \%$ vs $\mathrm{PJ} 68 \%, P=.002$ ).

A randomized study from France was criticized for the high overall mortality $(11 \%),{ }^{30}$ while a Spanish trial was the first to report significantly lower incidence of CR-POPF with a PG $(4 \%$ in PG and $18 \%$ in PJ, $P<.01)^{22}$; of note, however, they used a gastric partition technique with preservation of the gastro-epiploic arcade which is technically complex and not always possible oncologically.

A German trial did not find any statistically significant difference in the incidence of CR-POPF $^{31}$ ( $10 \%$ in PG vs $12 \%$ in PJ). A Belgian study used a stratified design based on the pancreatic ductal diameter ( $\leq 3 \mathrm{~mm}$ vs $>3 \mathrm{~mm}$ ) and showed a significantly lower rate of CR-POPF in the PG group (odds ratio [OR] 2.86, 95\% confidence interval $[\mathrm{CI}] 1.38-6.17 ; P=.002)$. In patients with duct diameter of less than or equal to $3 \mathrm{~mm}$, the CR-POPF rate was $24.5 \%$ in the PJ group vs $10.2 \%$ in the PG group; however, this apparent improvement did not translate into a statistically significant decrease in morbidity for unclear reasons. $^{32}$

In another Spanish trial randomizing 123 patients, Figueras et $\mathrm{al}^{33}$ reported a significantly lower incidence of CR-POPF in the PG group when compared to PJ group $(11 \%$ vs $33 \%$, $P=.006) .{ }^{33}$ In the German RECOPANC multicenter trial involving 320 patients, there was no significant difference found in the incidence of CR-POPF between the PG and PJ arms (20\% vs $22 \%, P=.6) .{ }^{23}$ In another RCT involving $90 \mathrm{pa}-$ tients randomized to an isolated Roux limb PJ versus PG, there was no statistically significant difference found in the incidence of CR-POPF $(8 \%$ vs $15 \%, P=.30) .{ }^{34}$ 
These RCTs have shown varied conclusions with respect to incidence of CR-POPF; however, the overall morbidity essentially remained equivalent across the majority of studies. Furthermore, none of the RCTs addressed the issue of a particular technique of anastomosis for the prevention of the more sinister POPF grade $\mathrm{C}$.

Meta-analyses for PG versus PJ. There are 17 meta-analyses that have been published on this topic with varied conclusions. The major problem has been the clinical heterogeneity in the individual randomized trials that have been analyzed. The earlier meta-analyses included a number of observational series as well as studies with varied techniques, all adding to this heterogeneity. ${ }^{35,36}$ The characteristics of selected meta-analyses (2006-2015) ${ }^{35-40}$ are highlighted in Table I.

In a recent meta-analysis by Menahem et $\mathrm{al}^{40}$ comparing PG versus PJ after PD, 7 RCTs involving a total of 1,121 patients were analyzed; the incidence of POPF was significantly less in patients undergoing PG than in those having PJ (11.2\% vs $18.7 \% ;$ OR $=0.53 ; 95 \%$ CI $0.38-0.75 ; P=.0003)$; however, the standard definition of POPF as set by the ISGPF was adopted in only 4 RCTs which made the combined analysis of RCTs using the nonstandard definitions problematic and introduced more potential heterogeneity.

The other factors that potentially may affect POPF, such as pancreatic duct stenting, octreotide, and extent of resection, were not distributed homogeneously among the RCTs. The differences in outcomes due to these unevenly distributed key factors have not been accounted for in the final analysis. There was no statistically significant difference found in the surrogate outcomes of pancreatic fistula, such as delayed gastric emptying, overall morbidity, and mortality among the 2 groups. Currently, no meta-analyses have included the large RECOPANC trial. Thus, there are major drawbacks in these meta-analyses that need to be addressed before firm conclusions can be drawn.

Adjunctive measures. Role of stenting. The role of stenting across the PA has been investigated as much for its potential to decrease the rate of POPF as to mitigate the severity of the POPF. The rationale is to divert pancreatic secretions away from the anastomosis as well as allegedly to guide more precise placement of sutures for duct-tomucosa anastomosis. ${ }^{41}$

In an RCT involving 120 patients, the patients who had external stenting had a significantly lower rate of POPF (not defined by the ISGPF definition but by a definition of clinical leakage by symptoms and need for drainage of a fluid collection) when compared to the nonstented group (3\% vs $15 \%$, $P=.027)$, but despite this finding, there were no statistically significant differences found in overall morbidity or hospital mortality. ${ }^{42}$

In another French RCT involving 158 patients with high-risk prognostic factors for CR-POPF, including soft pancreatic texture and a main pancreatic duct size $<3 \mathrm{~mm}$, external stenting was found to decrease CR-POPF and overall morbidity. The CR-POPF rate was $25 \%$ in the stented group vs $36 \%$ in the no-stent group. ${ }^{43}$ In another RCT from Japan involving 93 patients, among the patients with nondilated ducts, CR-POPFs were shown to occur significantly less often with external stenting versus no stenting ( $10 \%$ vs $40 \% ; P=.03)$, while in those patients with a dilated duct, there were no statistically significant differences found $(4 \%$ vs $8 \%){ }^{44}$

In another RCT involving 238 patients, internal stenting did not decrease the incidence of a pancreatic leak (non-ISGPF definition); however, this study was criticized for nonstandardization of the technique of PJ and PG in both groups and the inability to determine the rate of CR-POPFs in the database. $^{45}$ A recent RCT involving 328 patients powered for equivalence between internal and external stenting showed that CR-POPF rates were $18.9 \%$ and $24.4 \%$, respectively, with a conclusion tending to favor internal stenting but with wide confidence limits; the study, however, failed to stratify by fistula risk. ${ }^{46}$

In a recent (2016) Cochrane systematic review, ${ }^{47}$ the role of stents in decreasing CR-POPF after PD was uncertain due to the low quality of the evidence (relative risk $0.67,95 \%$ CI 0.39 to 1.14; 605 participants; 4 studies). The effect of external stents on the risk of CR-POPF, reoperation, DGE, and intra-abdominal collections when compared with internal stents was uncertain due to lowquality evidence, and further RCTs were deemed necessary. To summarize, the benefit of stenting the PA is not supported by high quality evidence.

Role of somatostatin analogues. There have been numerous studies exploiting the strategy of decreasing pancreatic secretions and thereby possibly the risk of pancreatic fistula by using somatostatin analogues, such as octreotide, pasireotide, etc. RCTs have shown conflicting results with regard to the value of perioperative somatostatin analogues. Benefits have been shown in European trials, but contradictory results have been reported in the early American trials. In an early European, randomized, multicenter trial involving 246 patients, perioperative use of octreotide was shown 
Table I. Characteristics of selected meta-analyses comparing PG vs PJ (2006-2015)

\begin{tabular}{|c|c|c|c|c|c|}
\hline$\#$ & Author and year & $\begin{array}{c}\text { Number of } \\
\text { RCTs included }\end{array}$ & $\begin{array}{c}\text { Number of } \\
\text { observational } \\
\text { studies included }\end{array}$ & $\begin{array}{l}\text { Extent of heterogeneity } \\
\qquad I^{2} \text { statistic }\end{array}$ & $\begin{array}{l}\text { Conclusion of } \\
\text { meta-analysis }\end{array}$ \\
\hline 1. & McKay $2006^{35}$ & $1 \mathrm{RCT}$ & 10 OCS & $\mathrm{NA}$ & PG better than PJ \\
\hline 2. & Wente, $2007^{36}$ & 3 RCTs & 13 OCS & $35.6 \%$ & $\begin{array}{l}\text { OCS- }>\text { PG superior over PJ; } \\
\text { RCTS- }>\text { PG and PJ have } \\
\text { equal results. }\end{array}$ \\
\hline 3. & Clerveus M 2014 ${ }^{37}$ & 7 RCTs & - & NA & $\begin{array}{l}\text { PG cannot be considered } \\
\text { superior to PJ due to } \\
\text { heterogeneity of trials } \\
\text { and absence of } \\
\text { difference in morbidity, } \\
\text { reoperation rates, and } \\
\text { mortality }\end{array}$ \\
\hline 4. & Hallet J $2015^{38}$ & 4 RCTs & - & $0 \%$ & PG decreases POPF rate \\
\hline 5. & WeiTaoQue MM $2015^{39}$ & 8 RCTs & - & $51.9 \%$ & PG preferred over PJ \\
\hline 6. & Benjamin Menahem $2015^{40}$ & 7 RCTs & 一 & $17 \%$ & $\begin{array}{l}\text { PG- }>\text { lower POPF rates and } \\
\text { biliary fistula rates }\end{array}$ \\
\hline
\end{tabular}

to decrease postoperative complications, especially in high-risk patients with malignancy $(38 \%$ in octreotide vs $65 \%$ in placebo). ${ }^{48}$

In another RCT involving 218 patients, prophylactic octreotide was shown to decrease the incidence of POPF rates $(9 \%$ in octreotide vs $19.6 \%$ in placebo; note, the definition of POPF was not according to the ISGPF). ${ }^{49}$ In contrast, in another RCT from the United States involving 211 patients undergoing PD randomized to octreotide or placebo, the study was stopped because intermediate analysis revealed that there would be no significant difference found if it were continued. ${ }^{50}$

In yet another prospective trial from Barcelona involving 62 patients undergoing PD who were randomized to octreotide versus placebo, there was no statistically significant difference found in the overall morbidity. ${ }^{51}$ Another potent somatostatin analogue, vapreotide, also failed to show any benefit in an RCT involving 275 patients. ${ }^{52}$ These inconsistent results found in the early trials were criticized mainly due to the lack of a standard definition of POPF when these were conducted.

A recent, single-institution RCT involving 300 patients comparing prophylactic pasireotide to placebo showed a significant benefit by decreasing CR-POPF rates $(7.9 \%$ vs $16.9 \% ; P<.02)$ and morbidity $(11.2 \%$ vs $25 \%) .{ }^{53}$ The cost-benefit ratio of pasireotide has been a potential area of concern, and currently, other studies are ongoing. Also, pasireotide has not been approved for POPF prophylaxis in many countries.

In an earlier meta-analysis involving $1,918 \mathrm{pa}-$ tients, somatostatin analogues were not found to decrease mortality but were associated with decreased overall morbidity and pancreas-specific complications. (OR 0.56 [0.39 to 0.81$] ; P=.002){ }^{54}$ The Cochrane review involving 21 trials concluded that perioperative somatostatin analogues may decrease perioperative complications but not mortality, ${ }^{55}$ but further, well-designed studies based on risk adjustment are warranted for appropriate patient selection.

Role of dual limb with isolated PJ. Isolation of the PJ from biliary drainage has been studied as a means to decrease POPF rates. The technique is based on the rationale that diversion of biliary secretions from the PA (site of pancreatic secretions into the lumen) may avoid activation of pancreatic proenzymes and, thereby, protect healing at the site of PJ. A single RCT involving 90 patients assessed this technique, and the isolated PJ was not associated with a decreased CR-POPF rate. ${ }^{34} \mathrm{~A}$ recent meta-analysis also was unable to demonstrate any statistically significant difference between a single Roux limb and a double Roux limb. ${ }^{56}$ Of note, this meta-analysis used several different definitions of POPF which made any sound comparison difficult.

Role of prophylactic drainage. The benefit of prophylactic drainage after PD has remained highly controversial with some retrospective evidence showing no benefit, ${ }^{57}$ although drains often aid in the detection of complications after pancreatic resections. ${ }^{58}$ In an early randomized trial involving $179 \mathrm{pa}-$ tients, the presence of prophylactic drain failed to reduce the complications after pancreatic resection ${ }^{59}$; however in a recent, multicenter RCT involving 137 
patients randomized to no drain versus drain, PD without drainage was associated with greater morbidity; the study was terminated early in view of an unacceptable increase in mortality from $3 \%$ to $12 \%$, thereby concluding that elimination of drainage in PD increased the severity of complications. ${ }^{60}$

The concept of selective drainage in high-risk cases has been brought forward by many experts, and the controversy was reappraised..$^{61,62}$ In an RCT assessing early drain removal in patients at low risk of CR-POPF, 114 patients were randomized to early (postoperative day [POD] 3) versus late (POD5 or beyond) and concluded that prolonged retention of a drain was associated with an increase in complications, hospital stay, and cost. ${ }^{63}$ In a post hoc reappraisal of the same trial with risk stratification, moderate/high-risk patients with POD1 drain amylase $<5,000 \mathrm{U} / \mathrm{L}$ had lesser rates of CR-POPF with early drain removal on POD3 $(4.2 \%$ vs $38.5 \%, P=.003){ }^{64}$

This protocol of selective drain placement and early removal was studied in a prospective study involving 260 patients by the same authors in the United States and Italy and found that overall CR-POPF rates were less after implementation of this protocol $(11.2 \%$ vs $20.6 \%, P=.001) .{ }^{65}$ A recent RCT from Germany compared rates of reintervention in 438 patients randomized to drainage versus no drainage; the overall reintervention rates were not found to differ significantly between the groups (drain $21.3 \%$ vs no-drain $16.6 \%$; $P=.0004)$, and there were no differences in morbidity and mortality; the rate of CR-POPF, however, was found to be significantly less in the nodrain group (drain $11.9 \%$ vs no-drain $5.7 \%$; $P=.030) \cdot{ }^{66}$ In light of the current evidence, we believe that prophylactic drainage can be avoided confidently in negligible/low-risk patients and early drain removal on POD3 can be practiced in moderate/high-risk patients when the drain fluid amylase activity on POD1 is less than 5,000 U/L.

Role of tissue sealants and patches. The role of tissue fibrin sealants has been explored as a strategy to decrease CR-POPF, either by topical application or by duct occlusion. In an RCT involving 125 patients randomized to topical application of fibrin glue versus no glue in the control arm, there was no difference in the rate of a pancreatic fistula $(26 \%$ in the fibrin glue arm vs $30 \%$ in the control arm; pancreatic fistula was defined by the authors' definition) and no significant difference in morbidity and duration of hospital stay. ${ }^{67}$

In another RCT assessing temporary fibrin glue occlusion of the main pancreatic duct, 80 patients underwent PD with duct occlusion with no statistically significant difference in the rate of complications. ${ }^{68}$ In a retrospective study analyzing the use of round ligament as a tissue patch over the PA, 57 PDs were performed with a pancreatic leak rate (local definition of leak, not the ISGPF definition) of 9\%; however, further studies are lacking. ${ }^{69}$ Currently, there is no high-level evidence in favor of use of fibrin, other substances (such as neoprene or Tissucol), or tissue patches in the prevention of POPF after PD.

Fistula risk score. In a prospectively validated trial, recognized risk factors for CR-POPF, such as a small duct, soft pancreatic parenchyma, high-risk pathology, and excessive blood loss, were evaluated during PD, and a Fistula Risk Sore (FRS) was developed. ${ }^{70}$ Clinical and economic outcomes were evaluated across 4 ranges of scores (negligible risk- 0 points; low risk -1 to 2 points; intermediate risk -3 to 6 points; and high risk -7 to 10 points); the FRS correlated strongly with development of a CR-POPF $(P<.001)$. Clinical outcomes, including complications, duration of stay, and readmission rates, also increased with increasing FRS.

The FRS was validated in other multi-institutional studies as well as in other settings (such as laparoscopic PD and cases without drain placement). ${ }^{71,72}$ The FRS has also been used to assess various strategies to decrease CR-POPF in a risk-adjusted fashion, ${ }^{41,73}$ in assessing surgeon performance visà-vis CR-POPF outcomes, in augmenting risk prediction for PD, and in predicting cost of care. ${ }^{3,74}$ Thus, the FRS has been validated as a strong tool with widespread applicability in clinical practice to predict the chance of a CR-POPF and also as a tool to compare outcomes across various studies. The FRS can be a reliable method to stratify patients in future studies.

Quality of life issues. The quality of life (QOL) after PD with respect to the type of reconstruction is another arena for potential research. In the RECOPANC trial, QOL scores were assessed using the EORTC QLQ-C30 and PAN26 questionnaires at 6- and 12-months postoperatively; the domains of emotional and social functioning fared better in the PG compared to PJ group $(P=.039)$, and financial problems occurred less often in the PG group $(P=.04)$; however, there were no data on comparison of preoperative scores between the 2 groups. ${ }^{23}$ The other retrospective study comparing PG and PJ found no statistically significant difference in QOL aspects, but the study was criticized for unbalanced groups. ${ }^{75}$

\section{DISCUSSION}

In this era of evidence-based medicine, pancreatic surgeons over the past 2 decades have rightly 
embarked on the mission of identifying the ideal method of pancreatico-enteric reconstruction after PD. Despite multiple randomized studies and meta-analyses, there is no clear evidence or universally accepted guidelines for how to construct the optimal PA after PD. During the past 2 decades, although the operative mortality has decreased dramatically, the overall morbidity remains high (about 50\%), and the serious morbidity from the PA has remained relatively unchanged.

It is also interesting to note that experienced, high-volume pancreatic surgeons and institutions, after their initial publications, have refrained from publishing further on this subject. It seems plausible that these surgeons and their teams matured over time to realize that after the initial refinements ensured improved acceptable outcomes, further refinements were difficult if not impossible, and any further work in that direction was deemed essentially ineffective.

The recent additional data have not aided the surgeon today because of the complex interplay of various factors and variables. Many studies have focused on one variable in isolation for what is essentially a complex situation. The multiple studies described above have failed to provide definitive, consistent, and convincing level 1 evidence that any one technique of PA is better than the others, either during the traditional open PD or more recently with the laparoscopic PD. The same holds true for control of the stump of the pancreatic remnant after a distal pancreatectomy. ${ }^{76}$

Considerable heterogeneity exists in the practice of PD across the world as shown by a recent survey involving 897 surgeons who perform PD. ${ }^{77}$ The findings reveal that the practices are quite diverse and varied, and this only reflects that no best practice truly exists currently. The survey has also shown considerable regional variations with respect to the use of a stent, somatostatin analogues, drainage practices, and other putative adjunctive strategies designed to minimize the risk of a CR-POPF. With respect to reconstruction, $\mathrm{PJ}$ remains the most common form of reconstruction as practiced by $88.7 \%$ of surgeons who participated in the survey.

A consistent practice of a single technique for the PA may lead to a lesser rate of complications and, therefore, might be preferable. Although this may sound more philosophical and less evidencebased, there is plenty of indirect evidence in the literature ${ }^{8,13}$ where the excellent results of a particular group with a particular technique are often not replicated by other groups, and one probable explanation could be that the comfort level and experience of the surgeon performing a new technique trumps any new and different techniques.

Practicing and mastering a repetitive, standardized technique can be a potential solution to evade the problem of CR-POPF, especially by surgeons early in their career. In contrast, experienced surgeons in high-volume centers can be expected to utilize different techniques of PA depending on the local characteristics of the operation, anatomy, and consistency of the pancreatic parenchyma in selected situations.

With the rapid advent of minimally invasive technology, laparoscopic and robot-assisted approaches have been explored regarding their possible influence on CR-POPF rates. ${ }^{78}$ Reconstruction with the assistance of a surgical microscope has also been shown to decrease pancreatic fistula rates (using a non-ISGPF definition) in one surgeon's experience. ${ }^{79}$ The precise, fine movement in multiple axes as offered by the robotic technology along with its magnified 3-dimensional visual has also been claimed to decrease the incidence of POPFs (using many different definitions of POPF) after pancreatic reconstruction using the robot. ${ }^{80,81}$ Currently, there is no robust evidence proving any advantages for these procedures with regard to CR-POPF rates, and the prospects of a randomized trial happening soon also appears doubtful given the extremely large cohorts necessary to prove superiority.

The debate concerning the ideal or the "best" form of PA remains unanswered despite the past 2 decades of RCTs and multiple meta-analyses. The best current technique for pancreato-enteric reconstruction may very well depend more on surgeon experience and comfort using the classic teachings of Halsted (meticulous technique, good blood supply, a tension-free anastomosis) and varying the technique depending on local characteristics of the pancreas and the risk factors in the individual patient.

Our review of $\mathrm{PJ}$ versus $\mathrm{PG}$, invaginating versus duct-to-mucosa, stents versus no stents, use or not of somatostatin analogues, and various anatomic constructs of the draining intestinal limbs has not really shown any to be consistently or convincingly better than the other. Perhaps the question "Do we need more studies?" ${ }^{2}$ should be asked not concerning the currently described techniques, but rather aimed at radically new and novel approaches or paradigms (as yet undescribed) that lead to better tissue healing of the intestine or stomach to the pancreatic remnant.

Currently, it appears that further randomized studies and meta-analyses using currently described 
techniques of PA are unlikely to reach a definitive conclusion unless novel approaches or specific intraoperative scenarios are incorporated in highquality RCTs after eliminating bias and heterogeneity. Until a truly radically new paradigm becomes available, certain recommendations can be made based on evidence accumulated so far (Table II).

\section{POSITION STATEMENT}

In conclusion, the position statement of the ISGPS on pancreatic anastomosis after PD is as follows (based on Table III):

(1) Neither the use of pancreaticogastrostomy nor pancreaticojejunostomy has been shown to result in any substantial difference in the incidence of CR-POPF rates after a pancreatico-enteric anastomosis.

(2) A consistent practice of a standardized technique may be a potential strategy to decrease the rate of CR-POPFs for surgeons early in their career, but experienced surgeons at high-volume centers can have lower POPF rates performing a variety of techniques in diverse situations (Table II).
(3) Internal and external stenting cannot be routinely recommended, but external stenting can be considered in high-risk glands.

(4) Certain somatostatin analogues appear to decrease the perioperative complications after PD in selected, highrisk situations but not mortality. To this extent, their routine use may be relevant only in high-risk patients.

(5) Prophylactic abdominal drainage can be avoided in patients with negligible/low risk for POPF. In patients with moderate/high risk, early drain removal on POD3 is recommended if drain fluid amylase activity on POD1 is $<5,000 \mathrm{U} / \mathrm{L}$.

(6) The use of specific suture materials, tissue sealants, and biologic patches cannot be recommended pending higher-level studies.

(7) The Fistula Risk Score is a predictive tool for clinically relevant POPF, and its incorporation into routine clinical practice may help in managing patients selectively for use of somatostatin analogues and peripancreatic drainage.

(8) Future studies should be very high-quality, multicenter RCTs evaluating specific intraoperative scenarios after eliminating bias and heterogeneity.

Table II. Suggested recommendations in diverse intraoperative situations

\begin{tabular}{|c|c|c|c|}
\hline No & Scenario & Recommended strategy & ISGPS concurrence \\
\hline 1 & $\begin{array}{l}\text { Preferred method of PA following PD } \\
\quad(\mathrm{PPPD} / \mathrm{cW})\end{array}$ & $\begin{array}{l}\text { PJ with duct-mucosa advised as anastomotic } \\
\text { technique }\end{array}$ & Moderate \\
\hline 2 & $\begin{array}{l}\text { Preferred method of PA in the presence of } \\
\text { high risk features for POPF - soft gland, } \\
\text { small duct }(<3 \mathrm{~mm}) \text {, fatty pancreas and } \\
\text { posteriorly located duct etc. }\end{array}$ & $\begin{array}{l}\text { PJ with duct-mucosa advised as anastomotic } \\
\text { technique }\end{array}$ & Moderate \\
\hline 3 & $\begin{array}{l}\text { Does vascular resection in PD change the } \\
\text { strategy of PA? }\end{array}$ & May not change the strategy & Strong \\
\hline 4 & $\begin{array}{l}\text { a. Preferred suture material for } \\
\text { constructing duct-mucosa PA } \\
\text { b. Preferred suture material for pancreatic } \\
\text { parenchymal sutures (taken either in } \\
\text { dunking or duct to mucosa PA) }\end{array}$ & $\begin{array}{l}\text { Synthetic absorbable (PDS 5,0) } \\
\text { Synthetic absorbable (PDS 4,0) }\end{array}$ & $\begin{array}{l}\text { Moderate } \\
\text { Moderate }\end{array}$ \\
\hline 5 & $\begin{array}{l}\text { Preferential practice of anastomotic } \\
\text { stenting }\end{array}$ & $\begin{array}{l}\text { Stent (external/internal) based on high } \\
\text { risk features for POPF }\end{array}$ & Weak \\
\hline 6 & $\begin{array}{l}\text { Preferential practice of using somatostatin } \\
\text { analogues }\end{array}$ & $\begin{array}{l}\text { Routine use may be relevant following PD } \\
\text { for high risk glands }\end{array}$ & Moderate \\
\hline 7 & $\begin{array}{l}\text { Role of isolated Roux-en Y PJ following PD } \\
\text { to decrease CR-POPF }\end{array}$ & Not indicated as a strategy & Strong \\
\hline 8 & $\begin{array}{l}\text { Preferential practice over prophylactic } \\
\text { drainage }\end{array}$ & $\begin{array}{l}\text { Routine prophylactic drainage but early } \\
\text { removal on POD3 if drain amylase is low }\end{array}$ & Moderate \\
\hline 9 & $\begin{array}{l}\text { Tissue sealant/biologic tissue patch usage } \\
\text { to reduce CR-POPF }\end{array}$ & Not indicated as a strategy & Strong \\
\hline 10 & $\begin{array}{l}\text { Following a leak from a PA, when a patient } \\
\text { is being re-explored for POPF grade } \mathrm{C} \text {, } \\
\text { role of pancreatic re-anastomosis. }\end{array}$ & Not advisable as a strategy & Strong \\
\hline
\end{tabular}

ISGPS concurrence rating: Strong $(>70 \%) /$ Moderate $(35 \%-70 \%) /$ Weak $(<35 \%)$.

$c W$, Classical Whipple resection; PPPD, pylorus-preserving pancreatoduodenectomy. 
Table III. Levels of evidence and ISGPS recommendation

\begin{tabular}{|c|c|c|c|c|}
\hline Variables & $\begin{array}{l}\text { Literature review } \\
\text { summary data }\end{array}$ & $\begin{array}{l}\text { Level of evidence } \\
\qquad(1 \text { to } 5) \text { and } \\
\text { evidence-based } \\
\text { recommendation } \\
(\text { A to } D)\end{array}$ & $\begin{array}{c}\text { ISGPS } \\
\text { recommendation } \\
\text { (Strong, Moderate, } \\
\text { Weak) }\end{array}$ & Justification \\
\hline PG vs PJ & $\begin{array}{l}\text { PG apparently seems } \\
\text { advantageous over PJ } \\
\text { although varied } \\
\text { heterogeneity seen in } \\
\text { existing RCTs }\end{array}$ & $\begin{array}{l}\text { Level 1B } \\
\text { Grade B }\end{array}$ & Moderate & $\begin{array}{l}\text { High level of } \\
\text { heterogeneity observed } \\
\text { in evidence. }\end{array}$ \\
\hline Invagination technique & $\begin{array}{l}\text { Safe technique and can } \\
\text { be preferred in soft } \\
\text { glands with narrow } \\
\text { duct }\end{array}$ & $\begin{array}{l}\text { Level 1B } \\
\text { Grade B }\end{array}$ & Moderate & $\begin{array}{l}\text { Adequate evidence } \\
\text { observed. }\end{array}$ \\
\hline $\begin{array}{l}\text { Duct to mucosa } \\
\text { technique }\end{array}$ & $\begin{array}{l}\text { Safe and common } \\
\text { technique of PJ }\end{array}$ & $\begin{array}{l}\text { Level 1B } \\
\text { Grade A }\end{array}$ & Strong & $\begin{array}{l}\text { Adequate evidence } \\
\text { observed. }\end{array}$ \\
\hline Binding PJ & $\begin{array}{l}\text { Safe but not associated } \\
\text { with lower frequency of } \\
\text { CR-POPF, morbidity, } \\
\text { and mortality. }\end{array}$ & $\begin{array}{l}\text { Level 1B } \\
\text { Grade B }\end{array}$ & Weak & $\begin{array}{l}\text { Consistent evidence is } \\
\text { lacking. }\end{array}$ \\
\hline Dual loop with isolated PJ & $\begin{array}{l}\text { Dual loop with isolated PJ } \\
\text { is not superior to single } \\
\text { loop }\end{array}$ & $\begin{array}{l}\text { Level 1A } \\
\text { Grade A }\end{array}$ & Strong & $\begin{array}{l}\text { Consistent evidence } \\
\text { observed. }\end{array}$ \\
\hline $\begin{array}{l}\text { Gastric partition } \\
\text { technique }\end{array}$ & $\begin{array}{l}\text { New technique of PG but } \\
\text { oncologically not } \\
\text { always feasible }\end{array}$ & $\begin{array}{l}\text { Level 1B } \\
\text { Grade B }\end{array}$ & Weak & $\begin{array}{l}\text { Adequate evidence is } \\
\text { currently lacking. }\end{array}$ \\
\hline PA stenting & $\begin{array}{l}\text { Benefit of stenting PA is } \\
\text { not well supported by } \\
\text { evidence. No advantage } \\
\text { of external over } \\
\text { internal stenting }\end{array}$ & $\begin{array}{l}\text { Level 1A } \\
\text { Grade B }\end{array}$ & Moderate & $\begin{array}{l}\text { Moderate level evidence } \\
\text { observed. }\end{array}$ \\
\hline Somatostatin analogues & $\begin{array}{l}\text { Somatostatin analogues } \\
\text { may reduce } \\
\text { perioperative } \\
\text { complications but not } \\
\text { mortality. }\end{array}$ & $\begin{array}{l}\text { Level 1B } \\
\text { Grade B }\end{array}$ & Moderate & $\begin{array}{l}\text { Adequate evidence } \\
\text { observed. }\end{array}$ \\
\hline Fistula Risk Score & $\begin{array}{l}\text { Risk scores correlate with } \\
\text { CR-POPF incidence }\end{array}$ & $\begin{array}{l}\text { Level 2A } \\
\text { Grade B }\end{array}$ & Moderate & $\begin{array}{l}\text { Adequate evidence } \\
\text { observed }\end{array}$ \\
\hline Prophylactic drainage & $\begin{array}{l}\text { To avoid in negligible/ } \\
\text { low-risk patients and } \\
\text { early drain removal in } \\
\text { moderate/high risk if } \\
\text { POD1 drain amylase is } \\
\text { low }\end{array}$ & $\begin{array}{l}\text { Level 2B } \\
\text { Grade B }\end{array}$ & Moderate & $\begin{array}{l}\text { Adequate evidence } \\
\text { observed }\end{array}$ \\
\hline Quality of life & $\begin{array}{l}\text { Global QOL is identical } \\
\text { in both PG and PJ } \\
\text { reconstruction }\end{array}$ & $\begin{array}{l}\text { Level 1B } \\
\text { Grade A }\end{array}$ & Weak & $\begin{array}{l}\text { Lack of adequate } \\
\text { evidence }\end{array}$ \\
\hline Tissue sealant & $\begin{array}{l}\text { No advantage of tissue } \\
\text { sealants }\end{array}$ & $\begin{array}{l}\text { Level 1B } \\
\text { Grade A }\end{array}$ & Strong & $\begin{array}{l}\text { Adequate evidence } \\
\text { observed }\end{array}$ \\
\hline Tissue patches & $\begin{array}{l}\text { No advantage of tissue } \\
\text { patches }\end{array}$ & $\begin{array}{l}\text { Level 2B } \\
\text { Grade B }\end{array}$ & Moderate & $\begin{array}{l}\text { Lack of adequate } \\
\text { evidence }\end{array}$ \\
\hline Duct occlusion & $\begin{array}{l}\text { No advantage of duct } \\
\text { occlusion }\end{array}$ & $\begin{array}{l}\text { Level 1B } \\
\text { Grade A }\end{array}$ & Strong & $\begin{array}{l}\text { Adequate evidence } \\
\text { observed }\end{array}$ \\
\hline
\end{tabular}

Oxford Centre for Evidence-Based Medicine, Levels of Evidence: Level 1A, systematic review with homogeneity of RCTs; Level 1B, individual RCT with narrow confidence interval; Level $2 A$, systematic review with homogeneity of cohort studies; Level $2 B$, individual cohort study; Level $3 A$, systematic review with homogeneity of case-control studies; Level 3B, individual case-control study; Level 4, case series. Grades of Recommendation: Grade A, consistent level 1 studies; Grade B, consistent level 2 or 3 studies or extrapolations from level 1 studies; Grade C, level 4 studies or extrapolations from level 2 or 3 studies; Grade D, level 5 evidence or troublingly inconsistent or inconclusive studies of any. 


\section{Furthermore, studies should be encouraged for the development and study of truly novel and new para- digms of promoting healing of PA.}

\section{REFERENCES}

1. Büchler MW, Wagner M, Schmied BM, Uhl W, Friess H, Z'graggen $\mathrm{K}$. Changes in morbidity after pancreatic resection: toward the end of completion pancreatectomy. Arch Surg 2003;138:1310-4.

2. Bassi C, Dervenis C, Butturini G, Fingerhut A, Yeo C, Izbicki J, et al. International Study Group on Pancreatic Fistula definition. Postoperative pancreatic fistula: an international study group (ISGPF) definition. Surgery 2005;138:8-13.

3. McMillan MT, Soi S, Asbun HJ, Ball CG, Bassi C, Beane JD, et al. Risk-adjusted outcomes of clinically relevant pancreatic fistula following pancreatoduodenectomy: a model for performance evaluation. Ann Surg 2016;264:344-52.

4. Gouma DJ, van Geenen RC, van Gulik TM, de Haan RJ, de Wit LT, Busch OR, et al. Rates of complications and death after pancreaticoduodenectomy: risk factors and the impact of hospital volume. Ann Surg 2000;232:786-95.

5. Bassi C, Marchegiani G, Dervenis C, Sarr M, Abu Hilal M, Adham M, et al. The 2016 update of the International Study Group (ISGPS) definition and grading of postoperative pancreatic fistula : 11 years after. Surgery 2016 (In press)

6. Andrews J, Guyatt G, Oxman AD, Alderson P, Dahm P, Falck-Ytter Y, et al. GRADE guidelines: 14. Going from evidence to recommendations: the significance and presentation of recommendations. J Clin Epidemiol 2013;66:719-25.

7. Berger AC, Howard TJ, Kennedy EP, Sauter PR, BowerCherry M, Dutkevitch S, et al. Does type of pancreaticojejunostomy after pancreaticoduodenectomy decrease rate of pancreatic fistula? A randomized, prospective, dualinstitution trial. J Am Coll Surg 2009;208:738-49.

8. Peng SY, Wang JW, Lau WY, Cai XJ, Mou YP, Liu YB, et al. Conventional versus binding pancreaticojejunostomy after pancreaticoduodenectomy: a prospective randomized trial. Ann Surg 2007;245:692-8.

9. Oussoultzoglou E, Bachellier P, Bigourdan JM, Weber JC, Nakano H, Jaeck D. Pancreaticogastrostomy decreased relaparotomy caused by pancreatic fistula after pancreaticoduodenectomy compared with pancreaticojejunostomy. Arch Surg 2004;139:327-35.

10. Marcus SG, Cohen H, Ranson SH. Optimal management of the pancreatic remnant after pancreaticoduodenectomy. Ann Surg 1995;222:635-45.

11. Bassi C, Falconi M, Molinari E, Mantovani W, Butturini G, Gumbs AA, et al. Duct-to-mucosa versus end-to-side pancreaticojejunostomy reconstruction after pancreaticoduodenectomy: results of a prospective randomized trial. Surgery 2003; 134:766-71

12. Bai X, Zhang Q, Gao S, Lou J, Li G, Zhang Y, et al. Duct-to-mucosa vs invagination for pancreaticojejunostomy after pancreaticoduodenectomy: a prospective, randomized controlled trial from a single surgeon. J Am Coll Surg 2016;222:10-8.

13. Casadei R, Ricci C, Silvestri S, Campra D, Ercolani G, D'Ambra M, et al. Peng's binding pancreaticojejunostomy after pancreaticoduodenectomy. An Italian, prospective, dual-institution study. Pancreatology 2013;13:305-9.

14. Targarona J, Barreda L, Pando E, Barreda C. Is Peng's pancreaticojejunal anastomosis more effective than mucosamucosa anastomosis in duodenopancreatectomy for pancreatic and peri-ampullary tumours? Cir Esp 2013;91: $163-8$
15. Kleespies A, Rentsch M, Seeliger H, Albertsmeier M, Jauch KW, Bruns CJ. Blumgart anastomosis for pancreaticojejunostomy minimizes severe complications after pancreatic head resection. Br J Surg 2009;96:741-50.

16. Strasberg SM, Drebin JA, Mokadam NA, Green DW, Jones KL, Ehlers JP, et al. Prospective trial of a blood supply-based technique of pancreaticojejunostomy: effect on anastomotic failure in the Whipple procedure. J Am Coll Surg 2002; 194:746-58.

17. Andrianello S, Pea A, Pulvirenti A, Allegrini V, Marchegiani G, Malleo G, et al. Pancreaticojejunostomy after pancreaticoduodenectomy: suture material and incidence of post-operative pancreatic fistula. Pancreatology 2016;16:138-41.

18. Jang JY, Kim SW, Park SJ, Park YH. Comparison of the functional outcome after pylorus-preserving pancreatoduodenectomy: pancreatogastrostomy and pancreatojejunostomy. World J Surg 2002;26:366-71.

19. Shrikhande SV, Barreto G, Shukla PJ. Pancreatic fistula after pancreaticoduodenectomy: the impact of a standardized technique of pancreaticojejunostomy. Langenbecks Arch Surg 2008;393:87-91.

20. Delcore R, Thomas JH, Pierce GE, Hermreck AS. Pancreatogastrostomy: a safe drainage procedure after pancreatoduodenectomy. Surgery 1990;108:641-5.

21. Telford GL, Mason GR. Pancreaticogastrostomy: clinical experience with a direct pancreatic-duct-to-gastric-mucosa anastomoses. Am J Surg 1984;147:832-7.

22. Fernández-Cruz L, Cosa R, Blanco L, López-Boado MA, Astudillo E. Pancreatogastrostomy with gastric partition after pylorus-preserving pancreatoduodenectomy versus conventional pancreatojejunostomy. Ann Surg 2008;248: 930-8.

23. Keck T, Wellner UF, Bahra M, Klein F, Sick O, Niedergethmann M, et al. Pancreatogastrostomy versus pancreatojejunostomy for RECOnstruction after PANCreatoduodenectomy (RECOPANC, DRKS 00000767): perioperative and long-term results of a multicenter randomized controlled trial. Ann Surg 2016;263:440-9.

24. Eckardt AJ, Klein F, Adler A, Veltzke-Schlieker W, Warnick P, Bahra M, et al. Management and outcomes of haemorrhage after pancreatogastrostomy versus pancreatojejunostomy. Br J Surg 2011;98:1599-607.

25. Schlitt HJ, Schmidt U, Simunec D, Jäger M, Aselmann H, Neipp M, et al. Morbidity and mortality associated with pancreatogastrostomy and pancreatojejunostomy following partial pancreatoduodenectomy. Br J Surg 2002;89:1245-51.

26. Nakamura H, Murakami Y, Uemura K, Hayashidani Y, Sudo T, Ohge $\mathrm{H}$, et al. Predictive factors for exocrine pancreatic insufficiency after pancreatoduodenectomy with pancreaticogastrostomy. J Gastrointest Surg 2009;13: 1321-7.

27. Hirono S, Murakami Y, Tani M, Kawai M, Okada K, Uemura K, et al. Identification of risk factors for pancreatic exocrine insufficiency after pancreaticoduodenectomy using a 13C-labeled mixed triglyceride breath test. World J Surg 2015;39:516-25.

28. Yeo CJ, Cameron JL, Maher MM, Sauter PK, Zahurak ML, Talamini MA, et al. A prospective randomized trial of pancreaticogastrostomy versus pancreaticojejunostomy after pancreaticoduodenectomy. Ann Surg 1995;222:580-8.

29. Bassi C, Falconi M, Molinari E, Salvia R, Butturini G, Sartori N, et al. Reconstruction by pancreaticojejunostomy versus pancreaticogastrostomy following pancreatectomy: results of a comparative study. Ann Surg 2005;242:767-71. 
30. Duffas JP, Suc B, Msika S, Fourtanier G, Muscari F, Hay JM, et al. French Associations for Research in Surgery. A controlled randomized multicenter trial of pancreatogastrostomy or pancreatojejunostomy after pancreaticoduodenectomy. Am J Surg 2005;189:720-9.

31. Wellner UF, Sick O, Olschewski M, Adam U, Hopt UT, Keck T. Randomized controlled single-center trial comparing pancreatogastrostomy versus pancreaticojejunostomy after partial pancreatoduodenectomy. J Gastrointest Surg 2012;16: 1686-95.

32. Topal B, Fieuws S, Aerts R, Weerts J, Feryn T, Roeyen G, et al. Belgian Section of Hepatobiliary and Pancreatic Surgery. Pancreaticojejunostomy versus pancreaticogastrostomy reconstruction after pancreaticoduodenectomy for pancreatic or periampullary tumours: a multicentre randomised trial. Lancet Oncol 2013;14:655-62.

33. Figueras J, Sabater L, Planellas P, Muñoz-Forner E, LopezBen S, Falgueras L, et al. Randomized clinical trial of pancreaticogastrostomy versus pancreaticojejunostomy on the rate and severity of pancreatic fistula after pancreaticoduodenectomy. Br J Surg 2013;100:1597-605.

34. ElNakeeb A, Hamdy E, Sultan AM, Salah T, Askr W, Ezzat H, et al. Isolated Roux loop pancreaticojejunostomy versus pancreaticogastrostomy after pancreaticoduodenectomy: a prospective randomized study. HPB (Oxford) 2014;16:713-22.

35. McKay A, Mackenzie S, Sutherland FR, Bathe OF, Doig C, Dort J, et al. Meta-analysis of pancreaticojejunostomy versus pancreaticogastrostomy reconstruction after pancreaticoduodenectomy. Br J Surg 2006;93:929-36.

36. Wente MN, Shrikhande SV, Müller MW, Diener MK, Seiler CM, Friess H, et al. Pancreaticojejunostomy versus pancreaticogastrostomy: systematic review and meta-analysis. Am J Surg 2007;193:171-83.

37. Clerveus M, Morandeira-Rivas A, Picazo-Yeste J, MorenoSanz C. Pancreaticogastrostomy versus pancreaticojejunostomy after pancreaticoduodenectomy: a systematic review and meta-analysis of randomized controlled trials. J Gastrointest Surg 2014;18:1693-704.

38. Hallet J, Zih FS, Deobald RG, Scheer AS, Law CH, Coburn NG, et al. The impact of pancreaticojejunostomy versus pancreaticogastrostomy reconstruction on pancreatic fistula after pancreaticoduodenectomy: meta-analysis of randomized controlled trials. HPB (Oxford) 2015;17:113-22.

39. Que W, Fang H, Yan B, Li J, Guo W, Zhai W, et al. Pancreaticogastrostomy versus pancreaticojejunostomy after pancreaticoduodenectomy: a meta-analysis of randomized controlled trials. Am J Surg 2015;209:1074-82.

40. Menahem B, Guittet L, Mulliri A, Alves A, Lubrano J. Pancreaticogastrostomy is superior to pancreaticojejunostomy for prevention of pancreatic fistula after pancreaticoduodenectomy: an updated meta-analysis of randomized controlled trials. Ann Surg 2015;261:882-7.

41. Sachs TE, Pratt WB, Kent TS, Callery MP, Vollmer CM Jr. The pancreaticojejunal anastomotic stent: friend or foe? Surgery 2013;153:651-62.

42. Poon RT, Fan ST, Lo CM, Ng KK, Yuen WK, Yeung C, et al. External drainage of pancreatic duct with a stent to reduce leakage rate of pancreaticojejunostomy after pancreaticoduodenectomy: a prospective randomized trial. Ann Surg 2007;246:425-35.

43. Pessaux P, Sauvanet A, Mariette C, Paye F, Muscari F, Cunha AS, et al. External pancreatic duct stent decreases pancreatic fistula rate after pancreaticoduodenectomy: prospective multicenter randomized trial. Ann Surg 2011;253: $879-85$.
44. Motoi F, Egawa S, Rikiyama T, Katayose Y, Unno M. Randomized clinical trial of external stent drainage of the pancreatic duct to reduce postoperative pancreatic fistula after pancreaticojejunostomy. Br J Surg 2012;99:524-31.

45. Winter JM, Cameron JL, Campbell KA, Chang DC, Riall TS, Schulick RD, et al. Does pancreatic duct stenting decrease the rate of pancreatic fistula following pancreaticoduodenectomy? Results of a prospective randomized trial. J Gastrointest Surg 2006;10:1280-90.

46. Jang JY, Chang YR, Kim SW, Choi SH, Park SJ, Lee SE, et al. Randomized multicentre trial comparing external and internal pancreatic stenting during pancreaticoduodenectomy. Br J Surg 2016. [Epub ahead of print].

47. Dong Z, Xu J, Wang Z, Petrov MS. Stents for the prevention of pancreatic fistula following pancreaticoduodenectomy. Cochrane Database Syst Rev 2016:CD008914.

48. Buchler M, Friess H, Klempa I, Hermanek P, Sulkowski U, Becker H, et al. Role of octreotide in the prevention of postoperative complications following pancreatic resection. Am J Surg 1992;163:125-31.

49. Montorsi M, Zago M, Mosca F, Capussotti L, Zotti E, Ribotta G, et al. Efficacy of octreotide in the prevention of pancreatic fistula after elective pancreatic resections: a prospective, controlled, randomized clinical trial. Surgery 1995;117:26-31.

50. Yeo CJ, Cameron JL, Lillemoe KD, Sauter PK, Coleman J, Sohn TA, et al. Does prophylactic octreotide decrease the rates of pancreatic fistula and other complications after pancreaticoduodenectomy? Results of a prospective randomized placebo-controlled trial. Ann Surg 2000;232: 419-29.

51. Fernández-Cruz L, Jiménez Chavarría E, Taurà P, Closa D, Boado MA, Ferrer J. Prospective randomized trial of the effect of octreotide on pancreatic juice output after pancreaticoduodenectomy in relation to histological diagnosis, duct size and leakage. HPB (Oxford) 2013;15:392-9.

52. Sarr MG. The potent somatostatin analogue vapreotide does not decrease pancreas-specific complications after elective pancreatectomy: a prospective, multicenter, double-blinded, randomized, placebo-controlled trial. J Am Coll Surg 2003;196:556-64.

53. Allen PJ, Gönen M, Brennan MF, Bucknor AA, Robinson LM, Pappas MM, et al. Pasireotide for postoperative pancreatic fistula. N Engl J Med 2014;370:2014-22.

54. Connor S, Alexakis N, Garden OJ, Leandros E, Bramis J, Wigmore SJ. Meta-analysis of the value of somatostatin and its analogues in reducing complications associated with pancreatic surgery. Br J Surg 2005;92:1059-67.

55. Gurusamy KS, Koti R, Fusai G, Davidson BR. Somatostatin analogues for pancreatic surgery. Cochrane Database Syst Rev 2013:CD008370.

56. Klaiber U, Probst P, Knebel P, Contin P, Diener MK, Büchler MW, et al. Meta-analysis of complication rates for single-loop versus dual-loop (Roux-en-Y) with isolated pancreaticojejunostomy reconstruction after pancreaticoduodenectomy. Br J Surg 2015;102:331-40.

57. Adham M, Chopin-Laly X, Lepilliez V, Gincul R, Valette PJ, Ponchon T. Pancreatic resection: drain or no drain? Surgery 2013;154:1069-77.

58. Shrikhande SV, Barreto SG, Shetty G, Suradkar K Bodhankar YD, Shah SB, et al. Postoperative abdominal drainage following major upper gastrointestinal surgery: single drain versus two drains. J Cancer Res Ther 2013;9:267-71.

59. Conlon KC, Labow D, Leung D, Smith A, Jarnagin W, Coit DG, et al. Prospective randomized clinical trial of the 
value of intraperitoneal drainage after pancreatic resection. Ann Surg 2001;234:487-93.

60. Van Buren G 2nd, Bloomston M, Hughes SJ, Winter J, Behrman SW, Zyromski NJ, et al. A randomized prospective multicenter trial of pancreaticoduodenectomy with and without routine intraperitoneal drainage. Ann Surg 2014; 259:605-12.

61. Strobel O, Buchler MW. Drainage after pancreaticoduodenectomy: controversy revitalized. Ann Surg 2014;259:613-5.

62. Pai E, Shrikhande SV. Drainage after pancreaticoduodenectomy: to step back may be the way forward, but are randomized controlled trials making us any wiser? Ann Surg 2016;263:e19.

63. Bassi C, Molinari E, Malleo G, Crippa S, Butturini G, Salvia R, et al. Early versus late drain removal after standard pancreatic resections: results of a prospective randomized trial. Ann Surg 2010;252:207-14.

64. McMillan MT, Malleo G, Bassi C, Butterini G, Salvia R, Roses R, et al. Drain management following pancreatoduodenectomy: reappraisal of a prospective, randomized trial using risk stratification. J Am Coll Surg 2015;221:798-809.

65. McMillan MT, Malleo G, Bassi C, Allegrini V, Casetti L, Drebin JA, et al. Multicenter, prospective trial of selective drain management for pancreatoduodenectomy using risk stratification. Ann Surg 2016. [Epub ahead of print].

66. Witzigmann H, Diener MK, Kißenkötter S, Rossion I, Bruckner T, Werner B, et al. No need for routine drainage after pancreatic head resection: the dual-center, randomized, controlled PANDRA Trial (ISRCTN04937707). Ann Surg 2016;264:528-37.

67. Lillemoe KD, Cameron JL, Kim MP, Campbell KA, Sauter PK, Coleman JA, et al. Does fibrin glue sealant decrease the rate of pancreatic fistula after pancreaticoduodenectomy? Results of a prospective randomized trial. J Gastrointest Surg 2004;8:766-72.

68. Suc B, Msika S, Fingerhut A, Fourtanier G, Hay JM, Holmières F, et al. Temporary fibrin glue occlusion of the main pancreatic duct in the prevention of intraabdominal complications after pancreatic resection: prospective randomized trial. Ann Surg 2003;237:57-65.

69. Iannitti DA, Coburn NG, Somberg J, Ryder BA, Monchik J, Cioffi WG. Use of the round ligament of the liver to decrease pancreatic fistulas: a novel technique. J Am Coll Surg 2006;203:857-64.

70. Callery MP, Pratt WB, Kent TS, Chaikof EL, Vollmer CM. A prospectively validated risk score accurately predicts pancreatic fistula after pancreatoduodenectomy. J Am Coll Surg 2013;216:1-14.
71. Shubert CR, Wagie AE, Farnell MB, Nagorney DM, Que FG, Reid Lombardo KM, et al. Clinical risk score to predict pancreatic fistula after pancreatoduodenectomy: independent external validation for open and laparoscopic approaches. J Am Coll Surg 2015;221:689-98.

72. Kunstman JW, Kuo E, Fonseca AL, Salem RR. Evaluation of a recently described risk classification scheme for pancreatic fistulae development after pancreaticoduodenectomy without routine post-operative drainage. HPB (Oxford) 2014;16:987-93

73. McMillan MT, Christein JD, Callery MP, Behrman SW, Drebin JA, Kent TS, et al. Prophylactic octreotide for pancreatoduodenectomy: more harm than good? HPB (Oxford) $2014 ; 16: 954-62$.

74. McMillan MT, Allegrini V, Asbun HJ, Ball CG, Bassi C, Beane JD, et al. Incorporation of procedure-specific risk into the ACS-NSQIP surgical risk calculator improves the prediction of morbidity and mortality after pancreatoduodenectomy. Ann Surg 2016. [Epub ahead of print].

75. Schmidt U, Simunec D, Piso P, Klempnauer J, Schlitt HJ. Quality of life and functional long-term outcome after partial pancreatoduodenectomy: pancreatogastrostomy versus pancreatojejunostomy. Ann Surg Oncol 2005;12:467-72.

76. Diener MK, Seiler CM, Rossion I, Kleeff J, Glanemann M, Butturini G, et al. Efficacy of stapler versus hand-sewn closure after distal pancreatectomy (DISPACT): a randomised, controlled multicentre trial. Lancet 2011;377: 1514-22.

77. McMillan MT, Malleo G, Bassi C, Sprys MH, Vollmer CM. Defining the practice of pancreatoduodenectomy around the world. HPB (Oxford) 2015;17:1145-54.

78. Croome KP, Farnell MB, Que FG, Reid-Lombardo KM, Truty MJ, Nagorney DM, et al. Total laparoscopic pancreaticoduodenectomy for pancreatic ductal adenocarcinoma: oncologic advantages over open approaches? Ann Surg 2014;260:633-8.

79. Wada K, Traverso LW. Pancreatic anastomotic leak after the Whipple procedure is reduced using the surgical microscope. Surgery 2006;139:735-42.

80. Boggi U, Signori S, De Lio N, Perrone VG, Vistoli F, Belluomini M, et al. Feasibility of robotic pancreaticoduodenectomy. Br J Surg 2013;100:917-25.

81. Boggi U, Amorese G, Vistoli F, Caniglia F, De Lio N, Perrone V, et al. Laparoscopic pancreaticoduodenectomy: a systematic literature review. Surg Endosc 2015;29:9-23.

82. Shrikhande SV, Qureshi SS, Rajneesh N, Shukla PJ. Pancreatic anastomosis after pancreaticoduodenectomy: do we need further studies? World J Surg 2005;29:1642-9. 